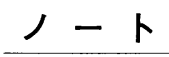

\title{
原子吸光法による天然水中の微量塩化物イオンの 間接定量
}

\author{
内海 喻, 松野 茂雄, 磯崎 昭徳 ${ }^{\circledR} *$
}

(1992 年 11 月 27 日受理)

\section{1 緒言}

フレーム原子吸光法で塩化物イオンを間接的に定量す る方法は, 既に幾つか報告されている. Pinta ${ }^{1)}$ は塩化 銀沈殿中の銀を测定し，5〜100 ppm の塩化物イオンを 定量している. 滕沼 ${ }^{2)}$ らは試料溶液にフェノールフタレ インを加え, 低温 $\left(3^{\circ} \mathrm{C}\right.$ 以下) に保ち, 塩化銀を生成さ せ溶解してから，銀の吸光度を測定する方法を提案し

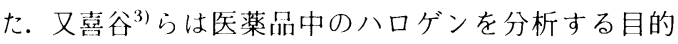
で，試料溶液に一'定過剩量の硝酸銀を加え，八ロゲン化 銀を沃別してから，沃液中の銀を測定し塩化物，臭化物 及びヨウ化物イオンの定量を試みている.その他二，三 報告4)5)されているが，定量範囲や妨害物質の除去対策 などを考慮して，生成した沈殿を利用する方法と，沃液 中の銀を測定するケ法に大別される。

著者らは，銀-ジエチルジチオカルバミン酸 (Ag-DDTC) 錯体を用いる微量塩化物イオンの間接紫 外吸光光度定量法を最近提案した6). すなわち, 硝酸酸 性とした試料溶液に一走量の硝酸銀溶液を加えて塩化銀 を生成させ，洰液中の銀イオンを Ag-DDTC キレート として四塩化炭素で抽出し, 紫外部の吸光度を測定する 方法, 及び生成した塩化銀をアンモニア水で溶解して利 用する方法である。この方法により, 天然水中の微量塩 化物イオンの走量が叮能であった。

本論文においては，嘅報 ${ }^{1) ~-5)}$ の原子吸光法を種々検 討し，また基本的には上䛉の吸光光度定量法 ${ }^{6)}$ を活用し てみた。 又, DDTC 試薬は用いず, 溶媒抽出操作も行 わないなど比較的簡易であり, 又高感度化されており, 天然水などに含まれる数 $\mathrm{ppm}$ 以下の塩化物イオンの定 量に適用できる。

*日本大学理厂学部I業化学科：101 東京都千代田区神 田駿河台 1-8-14
2 試薬及び装置

\section{$2 \cdot 1$ 試 薬}

塩化物イオン標準溶液 $\left(10^{-2} \mathrm{M}\right)$ 及び硝酸銀溶液 $\left(10^{-2} \mathrm{M}\right)$ は既報 ${ }^{6)}$ に従って調製し，使用に際して適宣 この溶液を希釈して用いた.

その他の試薬はいずれも市販特級品を用い，水は柴田 科学器械工業製の逆浸透純水装置 RD-10MT 型で精製 したものを使用した.

\section{$2 \cdot 2$ 装 置}

原子吸光分析装置：セイコー電子工業製 SAS-727 型 を使用し，バーナーは長さ $10 \mathrm{~cm}$ のスロット式であ る. 空気ーアセチレンフレームを用い, 光源は浜松ホト ニクス製の $\mathrm{Ag}$-中空陰極ランプ (単元素用) を使用し た。

吸引沪過器: メンブランフィルター (孔径 $0.45 \mu \mathrm{m}$ ) 付きの吸引沪過器であり，既報6)に略図を示した。

比色管：ガラス栓付き容量 $15 \mathrm{ml}$ のもの.

\section{3 結果と考察}

\section{$3 \cdot 1$ 定量操作と検量線}

3・1 1 定量操作 $(\mathbf{I})$ : 沪液法 塩化物イオンとし て $1 \times 10^{-4} \mathrm{M}(3.6 \mathrm{ppm})$ 以下の武料溶液 $10 \mathrm{ml}$ を比色 管に採り, $0.1 \mathrm{M}$ 硝酸溶液 $1 \mathrm{ml}$ 及び $1 \times 10^{-3} \mathrm{M}$ 硝酸銀 溶液 $1 \mathrm{ml}$ を加えて混合し, 10 分間放置する.メンブラ ンフィルター（孔径 $0.45 \mu \mathrm{m} ）$ を用いて吸引沪過し, 沃 液を別の比色管に受ける．沃液の一部を原子吸光分析用 セルにとり，波長 $328.1 \mathrm{~nm}$ における吸光度を測定す る. 標準溶液を用いて得られた検量線を Fig. 1(I) に示 す.

3・1・2 定量操作 (II)：塩化銀沈殿法試料溶液中 に妨害イオンが予想されるときは，次の操作によって生 


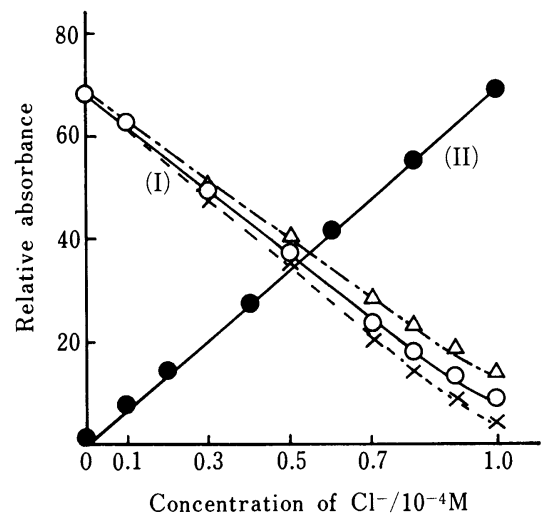

Fig. 1 Calibration curves of chloride ion (I) Filtrate method; $\bigcirc: 15^{\circ} \mathrm{C} ; \triangle: 25^{\circ} \mathrm{C} ; \times: 0^{\circ} \mathrm{C}$ (temperature on the formation of $\mathrm{AgCl}$ ) (II) AgCl-precipitate method

成した塩化銀沈殿中の銀を測定する.塩化物イオンとし 乙 $1 \times 10^{-4} \mathrm{M}$ 以下の試料溶液 $10 \mathrm{ml}$ を比色管に採り, $0.1 \mathrm{M}$ 硝酸溶液 $1 \mathrm{ml}$ 及び $5 \times 10^{-3} \mathrm{M}$ 硝酸銀溶液 $1 \mathrm{ml}$ を加えて混合し，10 分間放置する.メンブランフィル ターを用いて吸引沪過してから, フィルター上の塩化銀 を, 純水 $2 \mathrm{ml}$ を用いて 2 回吸引しながら洗浄する. 次 に $1 \mathrm{M}$ アンモニア水 $2 \mathrm{ml}$ を 2 回用いて塩化銀を完全 に溶解する. 更に純水 $8 \mathrm{ml}$ を用いて沪過器を洗浄しな がら加え全容を $12 \mathrm{ml}$ とする．この溶液を原子吸光分 析用セルにとり，波長 $328.1 \mathrm{~nm}$ における吸光度を測定 する. 検量線を Fig. 1 (II) に示す. Fig. 1 の検量線 （I）は，塩化銀生成時の温度の影響をやや受けるが，ほ ぼ化学量論的に反応が行われていることを示す．検量線 （II）は，多少試薬から試験值があるが，温度の影響も なく $1.0 \times 10^{-4} \mathrm{M}$ まで直線性のものが得られた。

\section{3 •2 銀の原子吸光測定条件について}

銀の測定波長としては，感度の良い $328.1 \mathrm{~nm}$ を用い ることにした，然焼ガスとして，アセチレンは水素を用 いた場合より多少感度が悪いとされる7が，取り扱いや すいので用いることにした。その他種々検討し，得られ た銀の最適測定条件を Table 1 に示す. 銀イオン $1.0 \times 10^{-4} \mathrm{M}$ 以下の濃度において, 再現性の良い直線の 検量線が得られたので，塩化物イオンの定量範囲を $1.0 \times 10^{-4} \mathrm{M}$ 以下とした. なお，実試料中の塭化物イ才 ンの定量で，妨害イオンが共存する場合を考慮して 0.1
Table 1 Optimum working conditions of measurement

$\begin{array}{ll}\text { Wavelength } & 328.1 \mathrm{~nm} \\ \text { Lamp current } & 10 \mathrm{~mA} \\ \text { Vertical position of burner holder } & 5 \mathrm{~mm} \\ \text { Air flow } & 19 \mathrm{l} / \mathrm{min} \\ \text { Acetylene flow } & 3.5 \mathrm{l} / \mathrm{min}\end{array}$

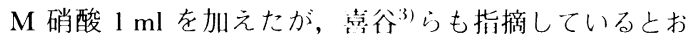
り，銀の検量線にはほとんど影響しなかった。

\section{$3 \cdot 3$ 塩化銀沈殿の生成条件}

定量操作 $(\mathrm{I})$ の塩化銀生成における放置時間の影響を 検討した．塩化物イオンとして $5 \times 10^{-5} \mathrm{M}$ の試料溶液 $10 \mathrm{ml}$ を採り, 液温 $15^{\circ} \mathrm{C}$ で放置時間を 1 分, 5 分, 10 分及び 30 分と変え，以下定量操作に従って吸光度を测 定した。その結果，5 分でほぼ満足すべき值が得られた が，再現性を考慮して 10 分放置することにした。

塩化銀生成時における温度の影響について実験した。 定量操作（I）で液温を $5^{\circ} \mathrm{C}, 15^{\circ} \mathrm{C}$ 及び $25^{\circ} \mathrm{C}$ とし各々 塩化物イオンの検量線を作成したところ，いずれも $0.7 \times 10^{-4} \sim 1.0 \times 10^{-4} \mathrm{M}$ の範井でわずかに湾曲を示 し，液温が高いほぼ大きく湾曲した $\{$ Fig. I（I）。これ は塩化物イオンが銀イオンと等モル近くになると，塩化 銀の溶解度が銀イオンによる共通イオン効果で抑えられ なくなったためと考えられる。しかし，検量線の再現性 は温度を一定にすれば良好であったので，塭化銀の沈殿 生成を恒温槽（例えば $15^{\circ} \mathrm{C}$ ）中で行い，同じ温度にお ける検量線を用いれば精度よく䇥量できる。

温度の影響を少なくする目的で，定量操作（II）のよ うに生成した塩化銀を利用する方法を検討したすすなわ ち，添加する硝酸銀溶液の濃度を $5 \times 10^{-3} \mathrm{M}$ とする と，過剩の銀イオンによる共通イオン効果で塩化銀の溶 解度が抑えられ，5 $25^{\circ} \mathrm{C}$ でほぼ一致した直線の検量線 が得られた \{Fig. 1(II)\}。其存イオンの影響も軽减でき た。

なお，藤沼ら ${ }^{2)}$ は塩化銀の沃別や洗浄操作の容易さな どのため，フェノールフタレインを加えている．又服部 $ら^{8)}$ は沈殿促進劑としてフェノールフタレインを用いて いる，著者らも試みてみたが，必ずしも添加する必要は なかった。

\section{$3 \bullet 4$ 共存イオンの影響}

$\mathrm{Ag}-\mathrm{DDTC}$ 錯体を用いる既報6)の沪液法（吸光光度 法）では，10 ppm の銅(II)，鈆，コバルト及びニッケ 
Table 2 Comparison of chloride ion concentrations in natural water samples obtained by filtrate, Ag-precipitate and mercury(II) thiocyanate methods

\begin{tabular}{cccc}
\hline \multirow{2}{*}{ Sample } & \multicolumn{3}{c}{$\mathrm{Cl}^{-}, \mathrm{ppm}$} \\
\cline { 2 - 4 } & Filtrate & $\mathrm{Ag}$-pre. & $\mathrm{Hg}(\mathrm{SCN})_{2}$ \\
\hline Underground & $2.3^{\mathrm{a})}$ & $2.2^{\mathrm{a})}$ & $2.2^{\mathrm{c})}$ \\
water & $(1.9)^{\mathrm{b})}$ & $(4.6)^{\mathrm{b})}$ & \\
River water & 2.8 & 2.8 & 2.8 \\
Rain water & 1.5 & 1.7 & 1.5 \\
\hline
\end{tabular}

Samples collected (location, date): underground water (Tanzawa, July 14, 1989), river water (Sagami R., July 14, 1989), rain water (Chiyoda-ku, Tokyo, July 6,1989$)$. a) mean of ten replicates; b) RSD ; c) analytical procedure of ref. 9 .

ルイオンはかなり影響を寺えたが，本法の沃液法では妨 害しなかった。銀イオンと反心して難溶性沈殿を生ずる 臭化物，ヨウ化物，シアン化物及び硫化物イオンは1 ppm，チ才硫酸イオンは $10 \mathrm{ppm}$ で妨害する。しかし， 塩化銀沈殿法を用いると，その沈殿がアンモ二ア水に溶 解しやすい奥化物及びシアン化物イオンを除いて, 妨害 をほとんど受けないという結果が得られた。

\section{$3 \cdot 5$ 実試料への適用}

本法を河川水，雨水及び地下水に適用した。結果を Table 2 に示す。沪液法及び塩化銀沈殿法を併記した。 両法の定量值はほぼ一致し, 又チ才シアン酸水銀 (II) 法 ${ }^{9}$ と比較しても満足のいく結果が得られた. 従って, 通常の試水では操作の簡便な沃液法でよいと考えられ る. 地下水について 10 回の繰り返し分析から, 本法の 相対標準偏差は，沪液法では $1.9 \%$, 沈殿法では $4.6 \%$ であった。

\section{文献}

1) M. Pinta: Methodes Physiques D'anal., 6, 268 (1970).

2) 藤沼 弘, 笠間和彦, 竹内賢志, 平野四蔵: 分析化 学, 19, 1487 (1970).

3) 喜谷喜徳, 竹村 洋, 小池 久: 分析化学, 22, 187 (1973).

4) W. Reichel, L. Acs: Anal. Chem., 41, 1886 (1969).

5) 東福義信, 平野四蔵: 分析化学, 20, 142 (1971).

6) 内海 喩, 松野茂雄, 磯崎昭徳: 分析化学, 40, 257 (1991).

7) 高久通夫, 束原 嚴, 渋谷晟二: 分析化学, $\mathbf{2 0}, 188$ (1971).

8) 服部只雄, 黒羽敏明: 分析化学, 13, 749 (1964). 服部只雄, 黑羽敏明, 淽谷戟二: 分析化学, 13, 853 (1964).

9）友成明久: 日化, 83,693（1962）.

Indirect determination of small amounts of chloride ion in natural water by AAS. Satori Utsumi, Shigeo MTsuno and Akinori Isozaki (Department of Industrial Chemistry, College of Science and Technology, Nihon University, 1-8-14, Kanda-Surugadai, Chiyoda-ku, Tokyo 101)

The present paper deals with a simple method for the indirect determination of chloride ion based on the measurement of silver by AAS. A sample solution $(10 \mathrm{ml})$ containing less than $1 \times 10^{-4} \mathrm{M}(3.6 \mathrm{ppm})$ chloride ion is placed in a glass tube with a stopper. One milliliter of $0.1 \mathrm{M}$ nitric acid and $1 \mathrm{ml}$ of $1 \times 10^{-3} \mathrm{M}$ silver nitrate are added, and mixed. After standing for $10 \mathrm{~min}$, the AgCl-precipitate is filtered with suction through a $0.45 \mu \mathrm{m}$ membrane filter. The absorption of silver ion in the filtrate is measured at 328.1 $\mathrm{nm}$ by an atomic absorption spectrometer. If some interfering ions such as iodide, thiosulfate and sulfide exist in the sample solution, the resulting AgCl-precipitate can be used for the determination of chloride. The precipitate on the filter is washed with water, dissolved completely in aqueous ammonia and the absorption of silver is measured at $328.1 \mathrm{~nm}$. The relative standard deviation obtained from the filtrate method for the determination of $2.3 \mathrm{ppm}$ chloride ion in an underground water sample was $1.9 \%(n=10)$.

(Received November 27, 1992)

\section{Keyword phrases}

indirect determination of chloride ion; natural water; AAS. 